\title{
Attachment Representations in Children with and without Attention-Deficit/Hyperactivity Disorder (ADHD)
}

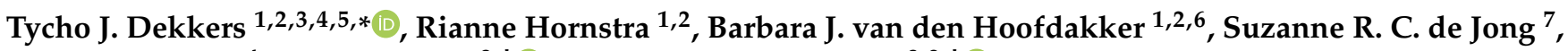 \\ Jessica V. Schaaf ${ }^{4}$, Guy Bosmans ${ }^{8,+}+$ and Saskia van der Oord ${ }^{8,9,+(i)}$
}

1 Department of Child and Adolescent Psychiatry, University Medical Center Groningen, University of Groningen, 9713 GZ Groningen, The Netherlands; r.hornstra@accare.nl (R.H.); b.van.den.hoofdakker@accare.nl (B.J.v.d.H.)

2 Accare Child Study Center, 9713 GZ Groningen, The Netherlands

3 Academic Center for Child and Adolescent Psychiatry, Levvel, 1105 AZ Amsterdam, The Netherlands

4 Department of Psychology, University of Amsterdam, 1018 WS Amsterdam, The Netherlands; j.v.schaa@@uva.nl

5 Department of Child and Adolescent Psychiatry, Amsterdam University Medical Centers (AUMC), 1105 AZ Amsterdam, The Netherlands

6 Department of Clinical Psychology and Experimental Psychopathology, University of Groningen, 9712 TS Groningen, The Netherlands

7 Clinical Neuropsychology Section, Department of Clinical, Neuro and Developmental Psychology, Vrije Universiteit, 1081 HV Amsterdam, The Netherlands; s.r.c.dejong@vu.nl

8 Faculty of Psychology and Educational Sciences, KU Leuven, 3000 Leuven, Belgium; guy.bosmans@kuleuven.be (G.B.); saskia.vanderoord@kuleuven.be (S.v.d.O.)

check for updates

Citation: Dekkers, T.J.; Hornstra, R.; van den Hoofdakker, B.J.; de Jong, S.R.C.; Schaaf, J.V.; Bosmans, G.; van der Oord, S. Attachment

Representations in Children with and without Attention-Deficit/ Hyperactivity Disorder (ADHD). Brain Sci. 2021, 11, 1516. https:// doi.org/10.3390/brainsci11111516

Academic Editor: Antonio Narzisi

Received: 18 October 2021

Accepted: 10 November 2021

Published: 16 November 2021

Publisher's Note: MDPI stays neutral with regard to jurisdictional claims in published maps and institutional affiliations.

Copyright: (C) 2021 by the authors. Licensee MDPI, Basel, Switzerland. This article is an open access article distributed under the terms and conditions of the Creative Commons Attribution (CC BY) license (https:// creativecommons.org/licenses/by/ $4.0 /)$.
9 Leuven Brain Institute, 3000 Leuven, Belgium

* Correspondence: t.dekkers@accare.nl

+ Shared senior authorship.

\begin{abstract}
Attention-Deficit/Hyperactivity Disorder (ADHD) in children is associated with several adverse family characteristics, such as higher parenting stress, more conflicted parent-child relationships, lower parental competence, and higher levels of parental psychopathology. Hence, children with ADHD more often grow up under suboptimal circumstances, which may impact the development of their attachment representations. Here, we investigated whether children with ADHD have more insecure and disorganized attachment representations than their typically developing peers, and which factors could explain this association. We included 104 children between 4 and 11 years old, 74 with ADHD (without Conduct Disorder) and 30 typically developing control children. Children completed a state-of-the-art story stem task to assess their attachment representation, and we measured parents' expressed emotion (as an index of parent-child relationship quality), parents' perceived sense of competence, parental education levels, and parent-rated ODD symptoms of the child. We found that, after controlling for multiple comparisons, children with ADHD had less secure and more ambivalent and disorganized attachment representations relative to their typically developing peers. These group differences were independent of comorbid ODD and parental education levels. There were no group differences on avoidant attachment representations. Explorative analyses within the ADHD group showed that attachment representations were not related to parentchild relationship quality, perceived parenting competence, parental education levels, and comorbid ODD symptoms. We conclude that children with ADHD disproportionately often have attachment problems. Although this conclusion is important, treatment implications of this co-occurrence are yet unclear as research on ADHD and attachment is still in its infancy.
\end{abstract}

Keywords: Attention-Deficit/Hyperactivity Disorder (ADHD); attachment; children; parenting; story stem; parent-child relationship 


\section{Introduction}

Attention-Deficit/Hyperactivity Disorder (ADHD) is a neurodevelopmental disorder characterized by age-inappropriate levels of inattention, hyperactivity, and/or impulsivity, causing impairment in several domains of life [1]. In children, the prevalence of ADHD is high, with $5-7 \%$ of children meeting diagnostic criteria [2,3]. In families of children with $\mathrm{ADHD}$, parenting stress is higher, parenting competence is lower, there is more parental psychopathology, parent-child relationships are more often conflicted, and the socioeconomic situation is disadvantageous relative to families of children without ADHD [4-6]. This suggests that children with ADHD disproportionately often grow up under adverse family conditions. As adverse family conditions often hinder the development of secure attachment [7], the link between ADHD and adverse family conditions has guided the hypothesis that children with ADHD more often have insecure and/or disorganized attachment representations. The current study therefore sets out to investigate whether school-age children with ADHD are less inclined to develop secure or less organized attachments than their typically developing peers.

Generally, three different attachment representations are distinguished. Sensitive and supportive parenting in response to stress will help the child to develop a secure base script, ultimately leading to a secure attachment representation [8]. On the other hand, insecure attachment develops when children have a lack of trust in the caregivers' availability when in need of protection or support. This can cause ambivalent or avoidant attachment representations, in which children either focus their attention exclusively on their caregivers or avoid their caregivers and rely on themselves. Finally, some children do not show coherence in their attachment behaviors (i.e., demonstrating disoriented or contradictory behaviors), which is classified as disorganized attachment [9]. Insecure and disorganized attachment has been linked to multiple forms of psychopathology, ranging from internalizing to externalizing disorders (see [10-12] for meta-analyses).

Despite its potential relevance, empirical research on the link between attachment and ADHD is scarce. A recent meta-analysis including 62 studies found a link between children's attention problems and attachment quality: children with more insecure and children with more disorganized attachment representations had more attention problems than children with secure or organized attachment representations, although the magnitude of the effects was modest [13]. A systematic review similarly concluded there is an association between ADHD and insecure attachment [14]. Upon further inspection of the studies included in these reviews, three significant limitations of the literature on ADHD and attachment emerged.

First, most studies investigated the link between attachment and ADHD symptoms in samples of typically developing children, or in children at risk for attachment problems [13]. Only a small proportion of the studies reviewed utilized a case-control design by comparing children with and without clinical diagnoses of ADHD, which is particularly necessary to estimate the relevance of attachment for children with ADHD. Generally, these casecontrol studies confirmed that children with ADHD had more insecure attachment patterns than their peers without ADHD [15-19], although some studies did not find such an association $[20,21]$.

Second, many studies investigating the link between ADHD and attachment did not control for comorbid disruptive behavior problems. Abundant literature shows a significant association between disruptive behavior and insecure attachment $[2,10]$. The relevance of controlling for disruptive behavior is further demonstrated by a study that found large differences in attachment representations between children with and without ADHD, which disappeared after controlling for disruptive behavior problems [20]. As ADHD and disruptive behavioral disorders often co-occur [22], and disruptive behavior disorders and insecure attachment are associated [2,10], controlling for disruptive behavior is imperative when assessing the link between ADHD and attachment [23].

A third limitation of the literature on ADHD and attachment relates to the measurement of attachment. From school-age, observational methods such as the Strange Situation 
Test [8] are less applicable because attachment behavior has become too subtle [24]. In addition, the scoring of insecure/disorganized attachment behavior may be confounded with ADHD characteristics using these measures, as behavioral (hyper)activity and rapid shifts in attention could be related to both [21,25]. Many studies on school-age children used self-report measures, which have different disadvantages: (i) self-report measures could invoke social desirability, especially on sensitive topics such as parent-child relationships; (ii) self-report is particularly unreliable in children with ADHD and/or Oppositional Defiant Disorder (ODD) [26]; (iii) a positive illusory bias is often reported in children with ADHD, meaning that children with ADHD systematically overestimate their own capacities [27]. A solid and well-established alternative to observational and self-report measures of attachment are representational measures of attachment, such as story stem procedures, in which children's cognitive attachment representations are derived from the completion of a story by the child [24,28].

In the current study, we take these limitations of previous studies into account, by investigating attachment representations in a carefully diagnosed sample of school-age children with and without ADHD, matched by age, sex, and intelligence, controlling for comorbid disruptive behavioral symptoms and using state-of-the-art story stem procedures to measure attachment representations. We hypothesize that children with ADHD have more insecure and more disorganized attachment representations, relative to typically developing children, and-based on the available literature on ADHD and insecure attachment- that this cannot be entirely explained by comorbid disruptive behavior. Then, we zoom into the group of children with ADHD to explore whether insecure and/or disorganized attachment representations in these children could be accounted for by parents' expressed emotion (as indicator of parent-child relationship quality), parents' perceived sense of competence, parental education levels, and children's comorbid ODD symptoms. Ultimately, this may guide interventions for children with ADHD and their families.

\section{Materials and Methods}

\subsection{Participants}

A total of 74 children with ADHD (combined presentation: $N=44$, inattentive presentation: $N=21$, hyperactive/impulsive presentation: $N=9$ ) and 30 Typically Developing (TD) children participated. Children with ADHD were recruited for a microtrial on behavioral parent training in six child mental healthcare outpatient clinics in the Netherlands [29]; TD children were recruited from the community. All children were between 4 and 11 years old and had an IQ of at least 70. Children included in the ADHD group were all previously diagnosed with ADHD in routine clinical care (which involves multi-informant assessment following evidence-base guidelines) and in addition had to meet criteria for any ADHD presentation on the Diagnostic Interview Schedule for Children (DISC-IV) [26]. Children were included in the TD group when not meeting criteria for ADHD on the same measure. None of the children were taking stimulant medication; children with an autism spectrum disorder or conduct disorder (CD) were excluded. Medical ethical approval was waived by the Medical Ethical Committee of the University Medical Center Groningen (METc2016/197).

\subsection{Measures}

\subsubsection{ADHD/ODD/CD}

The Disruptive Behavior Disorders module of the Dutch version of the structured Diagnostic Interview Schedule for Children (DISC-IV) [30] was administered to one of the parents/caretakers. This interview follows DSM-IV symptoms of ADHD, oppositional defiant disorder (ODD), and CD. Test-retest reliability and predictive validity (i.e., agreement of DISC-IV diagnoses with clinicians' ratings) of the DISC-IV are good ( $\kappa=0.79$ and $\kappa=0.72$, respectively) [26]. The DISC was used as a diagnostic measure (i.e., to include children with ADHD and to exclude children with $C D$ ), as well as to measure the number of ODD symptoms. 


\subsubsection{Intelligence}

Two subtests (Block Design and Vocabulary) of the Dutch Wechsler Intelligence Scale for Children (WISC-III) [31,32] or, with children younger than 6 years old, the Dutch Wechsler Preschool and Primary Scale of Intelligence (WPPSI-III) [33,34], were administered to estimate intelligence. These subtests correlate highly with full-scale intelligence quotients $[35,36]$. In case there was a recent intelligence score in the child's patient file, we used that score in order to not bother children unnecessarily.

\subsubsection{Parental Education Level}

Parent's highest level of education (8-point scale, with higher values indicating higher levels of education) was obtained. We could not obtain this information for two participants.

\subsubsection{Attachment Representations}

We used a story stem task to assess attachment representation. In this task, the researcher starts telling four stories to the child while using two dolls (one representing the child and the other the parent, gender and ethnicity matched) and a standardized set of attributes. Each story has an attachment-related theme, and the child is asked to finish all stories [24]. The themes of the four stories were "separation from parent" and "reunion with parent" (for all children), "hurt knee" and "monster in the bedroom" (for children 4-8 years old), and "in need of school assistance", and "fight with friend" (for children 8-12 years old). The task was originally developed as the Doll Story Completion Task to establish attachment in three-year-old children [37], and was adapted to assess attachment in middle childhood [28]. We used the task by Kerns and colleagues [24,38], who made three noticeable changes relative to the task developed by Granot and Mayseless: (i) some of the original stories did not elicit attachment themes when used in the United States, and were therefore replaced by new stories; (ii) stories were made less hypothetical by replacing fictive names by names of the child and his/her actual family members, and (iii) scoring was eased by removing siblings from the stories. Psychometric properties of the story stem task as established in previous studies were good: stability was moderate to high, and convergent validity was good as outcomes were related to questionnairebased attachment measures, and to maternal behavior, child adjustment, peer relationships, emotion regulation, and academic adjustment [38]. Note that each story stem dimension is strongly linked with the same label category in Ainsworth's [8] coding system in such a way that children scoring high on the dimension are most similar to the description of the category.

The session was recorded, and all tapes were scored independently afterwards by two raters (R.H. and S.d.J., interrater reliability $\kappa=0.82-0.96$ ). Raters followed a training in the assessments and scoring of the tapes. All disagreements were solved after discussion. Ultimately, this resulted in a score between 1 (no signs) and 5 (prototypical) on each of the four attachment representations (secure, ambivalent, avoidant, disorganized).

\subsubsection{Parent-Child Relationship: Expressed Emotion}

Five Minute Speech Samples (FMSS) [39] were collected of parents of all children in the ADHD group as a measure of Expressed Emotion (EE). EE reflects the quality of the parent-child relationship, and reliably predicts negative outcomes [40]. Parents were asked to talk about their child for five minutes, without any interruptions of the researcher. When parents stopped talking before the five minutes were finished, the researcher encouraged the parents to continue. Based on previous literature $[39,41]$, the FMSS yielded ratings on the initial statement (positive, neutral, or negative), warmth (high, moderate, or low), and relationship (positive, neutral, or negative), as well as the frequency of positive and critical comments. A total score of the ratings on the initial statement, warmth, and relationship was computed and served as the main dependent variable used in the analyses. If at least one of the ratings was low/negative, and the frequency of critical 
comments was higher than the positive comments, EE was considered high [39]. The speech sample was audio-taped and transcribed verbatim by research assistants. Two researchers (R.H. and S.d.J.) coded the first 20 transcripts independently from each other to establish reliability of the scoring; disagreement was discussed with senior author S.v.d.O., who completed specialized training in scoring of EE. Inter-rater reliability for the categorical ratings (initial statement; $\kappa=1.00$, warmth; $\kappa=0.82$, and relationship; $\kappa=1.00$ ) and intraclass correlation coefficients for the frequency of positive/critical comments $\left(\mathrm{ICC}_{\text {negative }}=0.974, \mathrm{ICC}_{\text {positive }}=0.945\right)$ were excellent .

\subsubsection{Parents' Perceived Sense of Competence}

The Parenting Sense of Competence scale (PSOC) [42] was used to assess parents' perceived competence as a parent. The PSOC consists of 17 items (e.g., "being a parent is manageable, and any problems are easily solved"), which are answered on a 6-point Likert scale ranging from 1 (strongly disagree) to 6 (strongly agree). Higher scores indicate higher parenting sense of competence. Higher ratings of child problems were related with lower scores on the PSOC, and psychometric properties (factor structure, internal consistency) were adequate [43].

\subsection{Procedure}

Eligible parents were provided with an information letter. When interested, procedures were explained and parents provided informed consent. Parents received an online questionnaire with demographic questions and the PSOC. The remaining measures were administered during a home visit or a visit to the clinic, in which the parents and the child were assessed simultaneously for about two hours. Parents received compensation for participating (EUR 10).

\subsection{Data-Analytic Approach}

As preliminary analyses, we used independent t-tests, Mann-Whitney tests (in case of non-normal distribution of data), and chi-square analyses to assess between-group differences on age, sex, intelligence, parental education levels, and ADHD and ODD symptoms.

As primary analyses, to test whether children with and without ADHD differ in attachment representations, we planned to use an ANCOVA with group (ADHD vs. TD) as independent variable and the continuous score on the attachment representation as dependent variable. However, as Levene's and Bartlett's test both indicated unequal variances (in combination with our unequal sample size), we instead performed multilevel regression analyses with group as fixed effect in which we freely estimated group variances in attachment representations. As we had four measures of attachment representations, this analysis was performed four times, once for each attachment representation.

We included age as covariate as the literature shows attachment and age are correlated [44]. However, we did not include IQ, ODD symptoms, and parental education levels as covariates because literature reports these variables are not only related to attachment but also to ADHD $[22,45,46]$. As such, adding these variables to the regression model would result in removing meaningful variance from the effect of ADHD, making them unsuitable as covariates (for statistical background, see [47]).

Instead, to understand whether associations between ADHD and attachment were independent of ODD symptoms or parental education levels, we performed separate analyses with ODD symptoms and parental education level as independent variables instead of group (note that these were bootstrapped regression analyses instead of multilevel regression analyses as ODD symptoms and parental education levels were measured continuously and thus homogeneity of regression slopes is not assumed).

As secondary analyses, to elucidate which children with ADHD are particularly at risk for insecure and disorganized attachment representations, we used bootstrapped (as assumptions were violated) hierarchical linear regression analyses to assess the influence 
of age and parental education levels (block 1), comorbid ODD symptoms (added in block 2), expressed emotions, and parenting sense of competence (both added in block 3) within the group of children with ADHD. Participants were excluded from specific secondary analyses when data were missing for any of the relevant measures (note: we had missing data on the PSOC for 7 participants and on the FMSS for 6 participants).

In both sets of analyses, we applied a Benjamini-Hochberg correction [48] for multiple testing because we used four indices of attachment. We conducted all analyses in SPSS (v.25).

\section{Results}

\subsection{Preliminary Analyses}

Groups did not differ in age, sex distribution, and intelligence (Table 1). Parental education level was higher for the TD children than for the children with ADHD. As expected, children with ADHD had more ODD symptoms than TD children.

Table 1. Sample characteristics (means and standard deviations, or distribution).

\begin{tabular}{cccc}
\hline & ADHD $(\boldsymbol{N}=\mathbf{7 4})$ & TD $(N=30)$ & \\
\hline Age & $8.60(1.62)$ & $8.03(1.82)$ & $t(102)=-1.57$ n.s. \\
Sex (\% boys) & $64.86 \%$ & $63.33 \%$ & $\chi^{2}(1)=0.02$ n.s. \\
IQ & $96.09(13.26)$ & $101.31(10.81)$ & $t(101)=1.89$ n.s. \\
Parental education level & $5.26(1.03)$ & $6.05(0.58)$ & $U=479.0^{* * *}$ \\
Inattention symptoms & $7.05(1.52)$ & $1.53(1.43)$ & $U=2119.5^{* * *}$ \\
Hyp.-Imp. symptoms & $6.24(2.16)$ & $1.27(1.29)$ & $U=2123.0^{* * *}$ \\
ODD symptoms & $2.89(2.14)$ & $0.73(1.29)$ & $U=1798.5^{* * *}$
\end{tabular}

Note: ${ }^{* * *} p<0.001,{ }^{* *} p<0.01$. For all variables except sex, means are reported, with standard deviations in parentheses. Abbreviations: ADHD = Attention-Deficit/Hyperactivity Disorder, Hyp.-Imp. = HyperactivityImpulsivity, $n . s .=$ not significant, $\mathrm{ODD}=$ Oppositional Defiant Disorder, $\mathrm{TD}=$ Typically Developing. Age was analyzed in months but reported in years to enhance readability.

\subsection{Primary Analyses: Group Differences}

Multilevel regression analyses with age as covariate revealed that children with ADHD differed significantly from TD children on three of the four attachment representations. Children with ADHD had lower scores on secure attachment representations and higher scores on ambivalent and disorganized attachment representations relative to TD children. Groups did not differ in avoidant attachment representations. Statistics on group differences are depicted in Table 2. Age was not significantly associated with any of the attachment representations.

Table 2. Attachment representations of children with and without ADHD.

\begin{tabular}{cccc}
\hline & ADHD $(N=74)$ & TD $(N=30)$ & \\
\hline Secure & $2.73(1.19)$ & $3.39(0.75)$ & $t(80.37)=3.49, p=0.001^{*}$ \\
Avoidant & $1.90(0.87)$ & $1.91(0.56)$ & $t(81.90)=0.26, p=0.793$ \\
Ambivalent & $1.46(0.62)$ & $1.23(0.33)$ & $t(92.46)=-2.57, p=0.012^{*}$ \\
Disorganized & $1.81(1.10)$ & $1.32(0.67)$ & $t(79.58)=-3.03, p=0.003^{*}$ \\
\hline
\end{tabular}

Note: Means are reported, with standard deviations in parentheses. Between-group differences were tested in a model with age as covariate. Abbreviations: ADHD = Attention-Deficit/Hyperactivity Disorder; TD = Typically Developing. * Significant after Benjamini-Hochberg correction.

Importantly, we found no significant effects on any attachment representation when ODD symptoms or parental education levels were analyzed as independent variables instead of group. This suggested that the observed associations between group and secure/ambivalent/disorganized attachment were independent of ODD symptoms or parental education levels (see Supplementary Materials for detailed results). 


\subsection{Secondary Analyses: Within ADHD Group Analyses}

None of the bootstrapped linear regression analyses within the ADHD group yielded any significant result. This indicated that age, parental education levels, parent-child relationship quality (as measured by parents' expressed emotion), and parents' perceived sense of competence were not associated with any of the attachment representations. For detailed results, see Table 3. The pattern of results did not change when only children with combined or inattentive presentations were considered (see Supplementary Materials Tables S3 and S4 for detailed results for these separate subgroups).

Table 3. Bootstrapped linear regression analyses within ADHD group.

\begin{tabular}{|c|c|c|c|c|}
\hline & B $(95 \%$ CI) & $S E$ & $\beta$ & $p$ \\
\hline \multicolumn{5}{|l|}{ Secure attachment } \\
\hline Age & $0.01(-0.01 ; 0.03)$ & 0.01 & 0.09 & 0.52 \\
\hline Parental education levels & $-0.03(-0.40 ; 0.37)$ & 0.20 & -0.03 & 0.86 \\
\hline ODD symptoms & $-0.01(-0.15 ; 0.15)$ & 0.07 & -0.02 & 0.90 \\
\hline Expressed Emotion & $0.13(-0.10 ; 0.37)$ & 0.11 & 0.15 & 0.29 \\
\hline Parenting Sense of Competence & $0.01(-0.02 ; 0.04)$ & 0.02 & 0.10 & 0.43 \\
\hline \multicolumn{5}{|l|}{ Avoidant attachment } \\
\hline Age & $-0.00(-0.01 ; 0.01)$ & 0.01 & -0.03 & 0.85 \\
\hline Parental education levels & $0.10(-0.08 ; 0.31)$ & 0.10 & 0.12 & 0.38 \\
\hline ODD symptoms & $-0.02(-0.15 ; 0.09)$ & 0.06 & -0.06 & 0.67 \\
\hline Expressed Emotion & $0.05(-0.10 ; 0.19)$ & 0.08 & 0.08 & 0.55 \\
\hline Parenting Sense of Competence & $-0.01(-0.03 ; 0.02)$ & 0.01 & -0.07 & 0.64 \\
\hline \multicolumn{5}{|l|}{ Ambivalent attachment } \\
\hline Age & $-0.01(-0.01 ; 0.00)$ & 0.00 & -0.15 & 0.15 \\
\hline Parental education levels & $0.07(-0.08 ; 0.20)$ & 0.07 & 0.12 & 0.44 \\
\hline ODD Symptoms & $-0.03(-0.09 ; 0.05)$ & 0.04 & -0.09 & 0.47 \\
\hline Expressed Emotion & $-0.02(-0.14 ; 0.11)$ & 0.06 & -0.04 & 0.76 \\
\hline Parenting Sense of Competence & $0.01(-0.01 ; 0.02)$ & 0.01 & 0.09 & 0.55 \\
\hline \multicolumn{5}{|l|}{ Disorganized attachment } \\
\hline Age & $-0.01(-0.02 ; 0.01)$ & 0.01 & -0.14 & 0.41 \\
\hline Parental education levels & $-0.04(-0.36 ; 0.20)$ & 0.15 & -0.04 & 0.78 \\
\hline ODD Symptoms & $0.04(-0.06 ; 0.16)$ & 0.06 & 0.08 & 0.49 \\
\hline Expressed Emotion & $-0.16(-0.37 ; 0.07)$ & 0.11 & -0.22 & 0.18 \\
\hline Parenting Sense of Competence & $-0.01(-0.04 ; 0.02)$ & 0.02 & -0.09 & 0.55 \\
\hline
\end{tabular}

Note: Independent variables were added hierarchically in three blocks, this table depicts the results from the final block containing all predictors. The $\beta$ column represents standardized coefficients; all other statistics are from bootstrapped analyses.

\section{Discussion}

The aim of this study was to investigate whether children with ADHD had more insecure and/or disorganized attachment representations relative to their peers without ADHD. Using story-stem procedures, we found that-in line with our hypothesis-children with ADHD had less secure attachment representations relative to typically developing children. Additionally, children with ADHD had more ambivalent and disorganized attachment representations. No between-group differences were found on avoidant attachment representations. Crucially, we found no effects of ODD symptoms and parental education on any attachment representation, which indicated that the link between insecure and disorganized attachment and ADHD was not explained by these factors.

The link between insecure and disorganized attachment and ADHD could be explained by several mechanisms. First, it may be more challenging to form a secure attachment relationship with children with ADHD relative to typically developing children, because of the inattentive, hyperactive, and impulsive behavior of these children. This may increase parenting stress, interfere with sensitive and responsive parenting behavior, and challenge the parent-child interaction, together challenging parents' ability to provide a secure base for their child $[20,23,49]$. 
Second, early life stress in general, and more specifically the insensitive/unresponsive caretaking behavior that leads to insecure attachment representations, may contribute to the development of ADHD. High levels of early life stress may have direct impact on the maturation of the brain [50,51], potentially contributing to neurodevelopmental psychopathology such as ADHD, whereas sensitive and responsive parenting protects against stress and stimulates children's brain development [52]. Moreover, prospective studies demonstrate that family risk factors (i.e., parental rejection, unresolved maternal mourning, parent-child relational problems, and mother-child attachment problems) increase the likelihood of developing ADHD later in childhood ([53-55], reviewed by [14]). Other compelling evidence for the temporal association between insecure attachment representations and later ADHD has been provided by the English and Romanian Adoptees Study, which shows that children growing up under severe institutional deprivation are more likely to display ADHD symptoms, with linear associations between the duration of deprivation and the severity of ADHD symptoms [56,57].

An explanation for the association between insecure attachment and ADHD could be that children with insecure attachment relationships with their parents constantly devote part of their attention to their safety and their caregiver (e.g., [58]), which impairs the development of their overall self-regulatory capacities (see [13] for an extensive review). A parent who provides secure base support during distress, however, consistently assists the child in regulating emotions and behavior, thereby facilitating the development of self-regulatory functioning [13,59]. Both causal directions (i.e., ADHD challenging secure attachment and insecure attachment contributing to ADHD symptoms) are plausible and it is most likely that challenging child behaviors, parenting problems, and early life stress interact in a synergistic manner during development [14], thereby contributing to the co-occurrence of ADHD and insecure attachment in children.

To better understand which characteristics of children with ADHD were particularly associated with insecure or disorganized attachment representations, we investigated four potentially relevant mechanisms within the ADHD group. Based on earlier work, we reasoned that parent-child relationship quality [60], parents' perceived sense of competence [61], parental education levels [62], and children's ODD symptoms [20] were all likely candidates. Our results, however, surprisingly demonstrated that none of these candidate mechanisms were particularly associated with any of the attachment representations within the group of children with ADHD. A potential explanation for the lack of effects on these proposed mechanisms could be that there is large heterogeneity in the causes of attachment problems, and therefore interactions between multiple factors are more likely than the univocal relationships that were currently tested. Another explanation could be that other mechanisms are more relevant in explaining attachment problems in children with ADHD. Here, we propose two related mechanisms that are derived from theoretical models on attachment, and should be empirically tested in future studies.

First, a recent model describing the development of attachment from a learning-theory perspective proposes that secure attachment is learned by reductions in cortisol after caregivers' support, which is a reinforcer in the safety conditioning of the child, thereby leading to increased trust in the caregiver [63]. More specifically, the contingency of the caregiver's support (i.e., the likelihood that the caregiver provides support when in stress) is related to the degree of support seeking, showing that expectancy-learning processes play a role in the development of secure attachment [64]. In children with ADHD, these learning processes may be disturbed. More specifically, children with ADHD may be less capable to learn the contingency in the safety signals of their caregivers, as many children with ADHD have an aberrant reward and punishment sensitivity [65-68]. This implies that children with ADHD typically need larger and more frequent reinforcement to increase their performance/functioning. Regarding the development of attachment, this lower capacity to learn from caregivers' safety signals would mean children with ADHD may develop less trust in their caregivers. In addition, parents of children with ADHD 
disproportionately often have elevated AHD symptoms themselves [69], which makes it more challenging to provide consistent and predictable parenting [70].

Second, a related mechanism to explain attachment problems in children with ADHD could come from the differential susceptibility theory, which posits that some children are more susceptible and others are more resilient concerning environmental influences, regardless whether these influences are negative or positive [71-73]. Empirical evidence for this theory was provided by a study that showed that VIPP-SD (Video-feedback Intervention to Promote Positive Parenting and Sensitive Discipline) was particularly effective in children with the $D R D 4$ 7-repeat allele, a polymorphism that was also linked to reward sensitivity and ADHD [74]. This tentatively suggests that a subgroup of children with ADHD is more susceptible to environmental influences, which could explain the increased levels of insecure and disorganized attachment, but would also imply an increased susceptibility to behavioral interventions [75].

\subsection{Strengths and Limitations}

The confidence in our findings is increased by several strengths of the study. Contrary to most studies on ADHD and attachment, we adopted a case-control design with a homogeneous ADHD group in which all children were medication-naive, and used a state-of-the-art story-stem task to measure attachment representations [24]. Moreover, we ascertained that the observed link between ADHD and insecure and disorganized attachment was independent of ODD symptoms and parental education levels.

Although all participating families of children with ADHD actively pursued behavioral treatment, a limitation of our study was that we potentially included a sample of relatively high-functioning families of children with ADHD, as established by average mean intelligence levels in the ADHD group, the low number of high scores on expressed emotions, the fact that none of the children were taking medication, and the fact that we excluded children with comorbid CD. However, it is most likely that between-group differences in attachment representations would rather be larger than smaller if our ADHD group would have been more severely impaired.

\subsection{Clinical Implications and Future Directions}

Based on our findings, we suggest considering both ADHD and attachment when assessing children referred with either ADHD behaviors and/or attachment-related problems. The co-occurrence of ADHD and insecure/disorganized attachment representations is likely explained by several mutually interactive mechanisms (i.e., ADHD behaviors challenging parenting, and early life stress predisposing for ADHD behaviors [12-14,23]) and a narrow vision focusing on only one of these aspects is unlikely to capture the full dynamics of the problems these children are encountering.

However, it is yet unclear whether the identification of attachment problems in children with ADHD would lead to different indications for interventions. A hypothesis that awaits empirical scrutiny is that children with ADHD and attachment problems particularly benefit from parenting interventions in which there is an explicit focus on relationship enhancement in addition to behavioral techniques, such as Parent Child Interaction Therapy (PCIT [76]) and VIPP-SD [77]. Crucially, to enhance the learning of children with ADHD, parents' reactions on support seeking behaviors should be explicit, clear, and frequent [63]. However, a recent meta-analysis on effective elements of behavioral parent training in children with ADHD (regardless of their attachment representations) suggested that foundational behavioral techniques such as stimulus-control and contingency management techniques were associated with the highest effectiveness [78]. In sum, a head-to-head comparison of regular behavioral parent training versus parenting interventions with a focus on relationship enhancement, investigated in children with ADHD with and without attachment problems, seems highly needed. Another recommendation for future intervention studies is to longitudinally investigate whether early treatment of ADHD symptoms 
fosters the development of secure attachment and, vice versa, whether early interventions aimed at the development of secure attachment representations also prevent later ADHD.

\section{Conclusions}

We demonstrated a link between ADHD and insecure/disorganized attachment representations in school-age children. This study adds to a small but important literature, and there is an urgent need for more studies on the clinical meaning and implications of the association between ADHD and attachment problems.

Supplementary Materials: The following are available online at https:/ /www.mdpi.com/article/10 $.3390 /$ brainsci11111516/s1, Table S1. Bootstrapped linear regression analyses with ODD symptoms and age as independent variables. Table S2. Bootstrapped linear regression analyses with parental education level and age as independent variables. Table S3. Bootstrapped linear regression analyses within ADHD group (only combined presentation. Table S4. Bootstrapped linear regression analyses within ADHD group (only inattentive presentation.

Author Contributions: Conceptualization: S.v.d.O., B.J.v.d.H., G.B.; methodology: J.V.S., T.J.D.; formal analysis: J.V.S., T.J.D.; investigation: R.H., S.R.C.d.J.; resources, S.v.d.O., B.J.v.d.H.; data curation: R.H., T.J.D.; writing—original draft preparation: T.J.D.; writing—review and editing: T.J.D., R.H., J.V.S., B.J.v.d.H., S.R.C.d.J., G.B., S.v.d.O.; supervision: S.v.d.O., B.J.v.d.H., G.B.; project administration: R.H.; funding acquisition, S.v.d.O., B.J.v.d.H. All authors have read and agreed to the published version of the manuscript.

Funding: This research was funded by the Dutch Organization for Health Research and Development (ZonMw), grant number 729300013 and by the Research Foundation Flanders (FWO), grant number G.0845.19N and the APC was funded by University of Leuven, University of Amsterdam and Accare.

Institutional Review Board Statement: The study was conducted according to the guidelines of the Declaration of Helsinki, and approved by the the Medical Ethical Committee of the University Medical Center Groningen (METc2016/197) on 30/06/2016 for the ADHD group and 11/11/2019 for the control group.

Informed Consent Statement: All parents provided active informed consent.

Data Availability Statement: The data are not publicly available because participating families did not consent for this.

Acknowledgments: We thank all participating children and parents, and we thank Hilde Huizenga (University of Amsterdam) for statistical consultation.

Conflicts of Interest: Dr. van den Hoofdakker has received royalties as one of the editors of "Sociaal Onhandig" (published by Van Gorcum), a Dutch book for parents that can be used in parent training. She has been involved in the development and evaluation of several parent and teacher training programs, without financial interests; she has been a member of Dutch ADHD guideline and practice standard groups. Dr. van der Oord has co-developed a planning-focused and solution-focused treatment, and other behavioral treatments, but has no financial interest in any of these. She has received research grants from ZonMw (The Netherlands Organization for Health Research and Development) and the FWO (The Flemish Organization for Scientific Research); she was an advisor of the Dutch ADHD guideline groups and is a member of a working group on ADHD of the health counsel of Belgium. The funders had no role in the design of the study; in the collection, analyses, or interpretation of data; in the writing of the manuscript, or in the decision to publish the results. The other authors report no potential conflict of interest.

\section{References}

1. American Psychiatric Association. Diagnostic and Statistical Manual of Mental Disorders, 5th ed.; American Psychiatric Association: Washington, DC, USA, 2013.

2. Thomas, R.; Sanders, S.; Doust, J.; Beller, E.; Glasziou, P. Prevalence of Attention-Deficit/Hyperactivity Disorder: A Systematic Review and Meta-analysis. Pediatrics 2015, 135, e994-e1001. [CrossRef] [PubMed]

3. Polanczyk, G.V.; Willcutt, E.G.; Salum, G.A.; Kieling, C.; Rohde, L.A. ADHD prevalence estimates across three decades: An updated systematic review and meta-regression analysis. Int. J. Epidemiol. 2014, 43, 434-442. [CrossRef] [PubMed] 
4. Deault, L.C. A Systematic Review of Parenting in Relation to the Development of Comorbidities and Functional Impairments in Children with Attention-Deficit/Hyperactivity Disorder (ADHD). Child Psychiatry Hum. Dev. 2009, 41, 168-192. [CrossRef] [PubMed]

5. Johnston, C.; Mash, E.J. Families of Children with Attention-Deficit/Hyperactivity Disorder: Review and Recommendations for Future Research. Clin. Child Fam. Psychol. Rev. 2001, 4, 183-207. [CrossRef]

6. Russell, G.; Ford, T.; Rosenberg, R.; Kelly, S.E. The association of attention deficit hyperactivity disorder with socioeconomic disadvantage: Alternative explanations and evidence. J. Child Psychol. Psychiatry Allied Discip. 2014, 55, 436-445. [CrossRef] [PubMed]

7. De Wolff, M.S.; Van Ijzendoorn, M.H. Sensitivity and attachment: A meta-analysis on parental antecedents of infant attachment. Child Dev. 1997, 68, 571-591. [CrossRef] [PubMed]

8. Ainsworth, M.D.S.; Blehar, M.C.; Waters, E.; Wall, S. Patterns of Attachment: A Psychological Study of the Strange Situation; Lawrence Erlbaum: Hillsdale, NJ, USA, 1978.

9. Main, M.; Cassidy, J. Categories of Response to Reunion with the Parent at Age 6: Predictable from Infant Attachment Classifications and Stable over a 1-Month Period. Dev. Psychol. 1988, 24, 415-426. [CrossRef]

10. Fearon, R.P.; Bakermans-Kranenburg, M.J.; van Ijzendoorn, M.; Lapsley, A.-M.; Roisman, G.I. The Significance of Insecure Attachment and Disorganization in the Development of Children's Externalizing Behavior: A Meta-Analytic Study. Child Dev. 2010, 81, 435-456. [CrossRef]

11. Madigan, S.; Atkinson, L.; Laurin, K.; Benoit, D. Attachment and internalizing behavior in early childhood: A meta-analysis. Dev. Psychol. 2013, 49, 672-689. [CrossRef]

12. Madigan, S.; Brumariu, L.E.; Villani, V.; Atkinson, L.; Lyons-Ruth, K. Representational and questionnaire measures of attachment: A meta-analysis of relations to child internalizing and externalizing problems. Psychol. Bull. 2016, 142, 367-399. [CrossRef]

13. Pallini, S.; Morelli, M.; Chirumbolo, A.; Baiocco, R.; Laghi, F.; Eisenberg, N. Attachment and attention problems: A meta-analysis. Clin. Psychol. Rev. 2019, 74, 101772. [CrossRef]

14. Storebø, O.J.; Rasmussen, P.D.; Simonsen, E. Association between Insecure Attachment and ADHD: Environmental Mediating Factors. J. Atten. Disord. 2016, 20, 187-196. [CrossRef]

15. Al-Yagon, M. Comorbid LD and ADHD in childhood: Socioemotional and behavioural adjustment and parents' positive and negative affect. Eur. J. Spéc. Needs Educ. 2009, 24, 371-391. [CrossRef]

16. Al-Yagon, M. Models of child-parent attachment in attention deficit hyperactivity disorder: Links to executive functions. Pers. Relatsh. 2018, 25, 280-298. [CrossRef]

17. Clarke, L.; Ungerer, J.; Chahoud, K.; Johnson, S.; Stiefel, I. Attention deficit hyperactivity disorder is associated with attachment insecurity. Clin. Child Psychol. Psychiatry 2002, 7, 179-198. [CrossRef]

18. Guttmann-Steinmetz, S.; Crowell, J.; Doron, G.; Mikulincer, M. Associations between mothers' and children's secure base scripts in ADHD and community cohorts. Attach. Hum. Dev. 2011, 13, 597-610. [CrossRef] [PubMed]

19. Sempio, O.L.; Fabio, R.A.; Tiezzi, P.; Cedro, C. Parental and teachers attachment in children at risk of ADHD and with ADHD. Life Span Disabil. 2016, 19, 57-77.

20. Franke, S.; Kissgen, R.; Krischer, M.; Sevecke, K. Attachment in Children with ADHD. J. Behav. Brain Sci. 2017, 07, 497-510. [CrossRef]

21. Hornstra, R.; Bosmans, G.; Hoofdakker, B.J.V.D.; De Meyer, H.; Van Der Oord, S. Self-reported attachment styles in children with and without attention-deficit/hyperactivity disorder (ADHD). Eur. Child Adolesc. Psychiatry 2019, 28, 1277-1280. [CrossRef]

22. Jensen, P.S.; Hinshaw, S.P.; Kraemer, H.C.; Lenora, N.; Newcorn, J.; Abikoff, H.B.; March, J.S.; Arnold, L.E.; Cantwell, D.P.; Conners, C.K.; et al. ADHD Comorbidity Findings from the MTA Study: Comparing Comorbid Subgroups. J. Am. Acad. Child Adolesc. Psychiatry 2001, 40, 147-158. [CrossRef] [PubMed]

23. Kissgen, R.; Franke, S. An attachment research perspective on ADHD. Neuropsychiatrie 2016, 30, 63-68. [CrossRef]

24. Kerns, K.A.; (Kent State University, Department of Psychology, Kent, OH, USA). Story Stem Procedures for Assessing Attachment Representations in Late Middle Childhood. Unpublished Manuscript. 2016.

25. Pallini, S.; Chirumbolo, A.; Morelli, M.; Baiocco, R.; Laghi, F.; Eisenberg, N. The relation of attachment security status to effortful self-regulation: A meta-analysis. Psychol. Bull. 2018, 144, 501-531. [CrossRef] [PubMed]

26. Shaffer, D.; Fisher, P.; Lucas, C.P.; Dulcan, M.K.; Schwab-Stone, M.E. NIMH Diagnostic Interview Schedule for Children Version IV (NIMH DISC-IV): Description, Differences from Previous Versions, and Reliability of Some Common Diagnoses. J. Am. Acad. Child Adolesc. Psychiatry 2000, 39, 28-38. [CrossRef]

27. Volz-Sidiropoulou, E.; Boecker, M.; Gauggel, S. The Positive Illusory Bias in Children and Adolescents with ADHD: Further Evidence. J. Atten. Disord. 2016, 20, 178-186. [CrossRef]

28. Granot, D.; Mayseless, O. Attachment security and adjustment to school in middle childhood. Int. J. Behav. Dev. 2001, 25, 530-541. [CrossRef]

29. Hornstra, R.; Van der Oord, S.; Staff, A.I.; Hoekstra, P.J.; Oosterlaan, J.; Van der Veen-Mulders, L.; Luman, M.; van den Hoofdakker, B.J. Which techniques work in behavioral parent training for children with ADHD? Evidence from a randomized controlled microtrial. J. Clin. Child Adolesc. Psychol. 2021, 1-16. [CrossRef] [PubMed]

30. Ferdinand, R.F.; van der Ende, J. DISC-IV: Diagnostic Interview Schedule for Children: Nederlandse Vertaling NIMH-DISC-IV (Dutch Translation of the DISC-IV); Sophia Children's Hospital: Rotterdam, The Netherlands, 1998. 
31. Kort, D.W.; Compaan, E.L.; Bleichrodt, N.; Resing, W.C.; Schittekatte, M.; Bosmans, M.; Verhaeghe, P. WISC-III NL Handleiding. (Dutch Manual); NIP: Amsterdam, The Netherlands, 2002.

32. Wechsler, D. WISC-III: Wechsler Intelligence Scale for Children: Manual; The Psychological Corporation: San Antonio, TX, USA, 1991.

33. Wechsler, D. Wechsler Preschool and Primary Scale of Intelligence—Revised; The Psychological Corporation: San Antonio, TX, USA, 1989. [CrossRef]

34. Hendriksen, J.G.M.; Hurks, P.P.M. Technical Manual WPPSI-III-NL; Pearson Assessment and Information B.V.: Amsterdam, The Netherlands, 2009.

35. Pierson, E.E.; Kilmer, L.M.; Rothlisberg, B.A.; McIntosh, D.E. Use of Brief Intelligence Tests in the Identification of Giftedness. J. Psychoeduc. Assess. 2011, 30, 10-24. [CrossRef]

36. Sattler, J. Assessment of Children: Cognitive Applications, 4th ed.; Jerome M. Sattler Publisher: San Diego, CA, USA, 2001.

37. Bretherton, I.; Ridgeway, D.; Cassidy, J. Assessing Internal Working Models of the Attachment Relationship. In Attachment in the Preschool Years: Theory, Research, and Intervention; Greenberg, M.T., Cicchetti, D., Cummings, E.M., Eds.; University of Chicago Press: Chicago, IL, USA; London, UK, 1990; pp. 273-308.

38. Kerns, K.A.; Brumariu, L.E.; Seibert, A. Multi-method assessment of mother-child attachment: Links to parenting and child depressive symptoms in middle childhood. Attach. Hum. Dev. 2011, 13, 315-333. [CrossRef] [PubMed]

39. Perez, E.; Turner, M.; Fisher, A.; Lockwood, J.; Daley, D. Linguistic Analysis of the Preschool Five Minute Speech Sample: What the Parents of Preschool Children with Early Signs of ADHD Say and How They Say It? PLoS ONE 2014, 9, e106231. [CrossRef]

40. Hooley, J.M. Expressed emotion: A review of the critical literature. Clin. Psychol. Rev. 1985, 5, 119-139. [CrossRef]

41. Wearden, A.J.; Tarrier, N.; Barrowclough, C.; Zastowny, T.R.; Rahill, A.A. A review of expressed emotion research in health care. Clin. Psychol. Rev. 2000, 20, 633-666. [CrossRef] [PubMed]

42. Gibaud-Wallston, J.; Wandersman, L.P. Parenting Sense of Competence Scale; Lawrence Erlbaum Associates: Mahwah, NJ, USA, 1978.

43. Johnston, C.; Mash, E.J. A Measure of Parenting Satisfaction and Efficacy. J. Clin. Child Psychol. 1989, 18, 167-175. [CrossRef]

44. Scharfe, E. Stability and change of attachment representations from cradle to grave. Attach. Process. Couple Fam. Ther. 2003, 64-84.

45. Dennis, M.; Francis, D.; Cirino, P.T.; Schachar, R.; Barnes, M.A.; Fletcher, J.M. Why IQ is not a covariate in cognitive studies of neurodevelopmental disorders. J. Int. Neuropsychol. Soc. 2009, 15, 331-343. [CrossRef] [PubMed]

46. Russell, A.E.; Ford, T.; Williams, R.; Russell, G. The Association between Socioeconomic Disadvantage and Attention Deficit/Hyperactivity Disorder (ADHD): A Systematic Review. Child Psychiatry Hum. Dev. 2015, 47, 440-458. [CrossRef] [PubMed]

47. Miller, G.A.; Chapman, J.P. Misunderstanding analysis of covariance. J. Abnorm. Psychol. 2001, 110, 40-48. [CrossRef]

48. Benjamini, Y.; Hochberg, Y. Controlling the False Discovery Rate: A Practical and Powerful Approach to Multiple Testing. J. R. Stat. Soc. Ser. B 1995, 57, 289-300. [CrossRef]

49. Verhage, M.L.; Schuengel, C.; Madigan, S.; Fearon, R.M.P.; Oosterman, M.; Cassibba, R.; Bakermans-Kranenburg, M.J.; van Ijzendoorn, M.H. Narrowing the transmission gap: A synthesis of three decades of research on intergenerational transmission of attachment. Psychol. Bull. 2016, 142, 337-366. [CrossRef] [PubMed]

50. Chen, Y.; Baram, T.Z. Toward Understanding How Early-Life Stress Reprograms Cognitive and Emotional Brain Networks. Neuropsychopharmacology 2015, 41, 197-206. [CrossRef] [PubMed]

51. Bosmans, G.; Young, J.F.; Hankin, B.L. NR3C1 methylation as a moderator of the effects of maternal support and stress on insecure attachment development. Dev. Psychol. 2018, 54, 29-38. [CrossRef] [PubMed]

52. Bernier, A.; Calkins, S.D.; Bell, M.A. Longitudinal Associations between the Quality of Mother-Infant Interactions and Brain Development Across Infancy. Child Dev. 2016, 87, 1159-1174. [CrossRef]

53. Lifford, K.J.; Harold, G.T.; Thapar, A. Parent-Child Relationships and ADHD Symptoms: A Longitudinal Analysis. J. Abnorm. Child Psychol. 2007, 36, 285-296. [CrossRef]

54. Rochford, L.G. Attending to Attachment: The Relation between Attention-Deficit/Hyperactivity Disorder and Mother-Child Attachment in Early Childhood. Ph.D. Dissertation, University of Chapel Hill, Chapel Hill, NC, USA, 2005.

55. Skovgaard, A.M. Mental health problems and psychopathology in infancy and early childhood. Dan. Med. Bull. 2010, 57, B4193.

56. Stevens, S.E.; Sonuga-Barke, E.J.S.; Kreppner, J.M.; Beckett, C.; Castle, J.; Colvert, E.; Groothues, C.; Hawkins, A.; Rutter, M. Inattention/Overactivity Following Early Severe Institutional Deprivation: Presentation and Associations in Early Adolescence. J. Abnorm. Child Psychol. 2007, 36, 385-398. [CrossRef]

57. Kreppner, J.; O'Connor, T.G.; Rutter, M.L. English and Romanian Adoptees Study Team Can Inattention/Overactivity Be an Institutional Deprivation Syndrome? J. Abnorm. Child Psychol. 2001, 29, 513-528. [CrossRef]

58. Bosmans, G.; Braet, C.; Koster, E.; De Raedt, R. Attachment Security and Attentional Breadth toward the Attachment Figure in Middle Childhood. J. Clin. Child Adolesc. Psychol. 2009, 38, 872-882. [CrossRef] [PubMed]

59. Nordling, J.K.; Boldt, L.J.; O’Bleness, J.; Kochanska, G. Effortful control mediates relations between children's attachment security and their regard for rules of conduct. Soc. Dev. 2015, 25, 268-284. [CrossRef] [PubMed]

60. Gravener, J.A.; Rogosch, F.A.; Oshri, A.; Narayan, A.J.; Cicchetti, D.; Toth, S.L. The relations among maternal depressive disorder, maternal expressed emotion, and toddler behavior problems and attachment. J. Abnorm. Child Psychol. 2012, 40, 803-813. [CrossRef] [PubMed] 
61. Gelkopf, M.; Jabotaro, S.E. Parenting style, competence, social network and attachment in mothers with mental illness. Child Fam. Soc. Work. 2012, 18, 496-503. [CrossRef]

62. Jzendoorn, M.H.v.; Bakermans-Kranenburg, M.J. Invariance of adult attachment across gender, age, culture, and socioeconomic status? J. Soc. Pers. Relat. 2010, 27, 200-208. [CrossRef]

63. Bosmans, G.; Bakermans-Kranenburg, M.J.; Vervliet, B.; Verhees, M.W.; van Ijzendoorn, M.H. A learning theory of attachment: Unraveling the black box of attachment development. Neurosci. Biobehav. Rev. 2020, 113, 287-298. [CrossRef] [PubMed]

64. Bosmans, G.; Waters, T.E.A.; Finet, C.; De Winter, S.; Hermans, D. Trust development as an expectancy-learning process: Testing contingency effects. PLoS ONE 2019, 14, e0225934. [CrossRef] [PubMed]

65. van der Oord, S.; Tripp, G. How to Improve Behavioral Parent and Teacher Training for Children with ADHD: Integrating Empirical Research on Learning and Motivation into Treatment. Clin. Child Fam. Psychol. Rev. 2020, 1-28. [CrossRef]

66. Tripp, G.; Wickens, J. Research Review: Dopamine transfer deficit: A neurobiological theory of altered reinforcement mechanisms in ADHD. J. Child Psychol. Psychiatry 2008, 49, 691-704. [CrossRef]

67. Luman, M.; Oosterlaan, J.; Sergeant, J.A. The impact of reinforcement contingencies on AD/HD: A review and theoretical appraisal. Clin. Psychol. Rev. 2005, 25, 183-213. [CrossRef] [PubMed]

68. Houbrechts, M.; Cuyvers, B.; Goossens, L.; Bijttebier, P.; Bröhl, A.S.; Calders, F.; Chubar, V.; Claes, S.; Geukens, F.; Van Leeuwen, K.; et al. Parental support and insecure attachment development: The cortisol stress response as a moderator. Attach. Hum. Dev. 2021, 1-13. [CrossRef]

69. Faraone, S.V.; Perlis, R.H.; Doyle, A.E.; Smoller, J.W.; Goralnick, J.J.; Holmgren, M.A.; Sklar, P. Molecular Genetics of AttentionDeficit/Hyperactivity Disorder. Biol. Psychiatry 2005, 57, 1313-1323. [CrossRef]

70. Chronis-Tuscano, A.; Raggi, V.L.; Clarke, T.L.; Rooney, M.; Diaz, Y.; Pian, J. Associations between Maternal AttentionDeficit/Hyperactivity Disorder Symptoms and Parenting. J. Abnorm. Child Psychol. 2008, 36, 1237-1250. [CrossRef]

71. Ellis, B.J.; Boyce, W.T.; Belsky, J.; Bakermans-Kranenburg, M.J.; van Ijzendoorn, M.H. Differential susceptibility to the environment: An evolutionary-neurodevelopmental theory. Dev. Psychopathol. 2011, 23, 7-28. [CrossRef] [PubMed]

72. Belsky, J. Differential Susceptibility to Environmental Influences. Int. J. Child Care Educ. Policy 2013, 7, 15-31.

73. Belsky, J.; Bakermans-Kranenburg, M.J.; van IJzendoorn, M.H. For Better and for Worse: Differential Susceptibility to Environmental Influences. Curr. Dir. Psychol. Sci. 2016, 16, 300-304. [CrossRef]

74. Bakermans-Kranenburg, M.J.; van Ijzendoorn, M.; Buisman-Pijlman, F.; Mesman, J.; Juffer, F. Experimental evidence for differential susceptibility: Dopamine D4 receptor polymorphism (DRD4 VNTR) moderates intervention effects on toddlers' externalizing behavior in a randomized controlled trial. Dev. Psychol. 2008, 44, 293-300. [CrossRef] [PubMed]

75. Van den Hoofdakker, B.J.; Nauta, M.H.; Dijck-Brouwer, D.A.J.; Van Der Veen-Mulders, L.; Sytema, S.; Emmelkamp, P.M.G.; Minderaa, R.B.; Hoekstra, P.J. Dopamine transporter gene moderates response to behavioral parent training in children with ADHD: A pilot study. Dev. Psychol. 2012, 48, 567-574. [CrossRef] [PubMed]

76. Eyberg, S. Parent-child interaction therapy: Integration of traditional and behavioral concerns. Child Fam. Behav. Ther. 1988, 10, 33-46. [CrossRef]

77. Van Zeijl, J.; Mesman, J.; van Ijzendoorn, M.; Bakermans-Kranenburg, M.J.; Juffer, F.; Stolk, M.N.; Koot, H.M.; Alink, L.R.A. Attachment-based intervention for enhancing sensitive discipline in mothers of 1- to 3-year-old children at risk for externalizing behavior problems: A randomized controlled trial. J. Consult. Clin. Psychol. 2006, 74, 994-1005. [CrossRef]

78. Dekkers, T.J.; Hornstra, R.; van der Oord, S.; Luman, M.; Hoekstra, P.J.; Groenman, A.P.; van den Hoofdakker, B.J. Meta-Analysis: Which Components of Parent Training Work for Children with Attention-Deficit/Hyperactivity Disorder? J. Am. Acad. Child Adolesc. Psychiatry 2021. [CrossRef] 